\title{
Characterization OF INDOOR PROPAgation Properties and Performance Evaluation for 2.4GHZ BAND WI-FI.
}

\author{
Emmanuel A. Ubom ${ }^{1}$, Aloysius C. Akpanobong ${ }^{2}$ and Idaresit I. Abraham ${ }^{1}$ \\ ${ }^{1}$ Department of Electrical and Electronic Engineering, Akwa Ibom State University, Ikot \\ Akpaden, Mkpat Enin, Nigeria. \\ ${ }^{2}$ Department of Computer Science, Akwa Ibom State University, Nigeria.
}

\begin{abstract}
Indoor wireless systems poses one of the biggest design challenges although it is the most flexible and easily deployable method of implementing Local Area Networks. This difficulty in predicting the propagation of radio frequency wave in indoor environments is caused by reflection, refraction, diffraction and scattering of signals due to closed proximities to furniture, walls, human beings, and reflectors like ceiling, mirrors and glasses. To help improve the user experience and guarantee good quality of service in indoor situations, the research investigated the throughput and attenuation effect on signal with respect to 4, 5, 6 and 9 inches sizes of blocks walls respectively. The characterized Path-loss exponent was 1.999 and differed from the free space model, Wall and Floor Factor model and ITU model by $53.54 \mathrm{~dB}, 6.42 \mathrm{~dB}$ and $6.85 \mathrm{~dB}$ respectively.
\end{abstract}

\section{KEYWORDS}

Throughput, Pathloss, Attenuation, Data stream

\section{INTRODUCTION}

The importance of resources sharing and access to information in today's 21 century society cannot be over-emphasized. Networking has made it possible for offices to share Printers, File Servers, Email system, and a single Internet connection transmitting data from one system to another most especially in multiple offices environments. Whether as a Local Area Network (LAN), Wide Area Network (WAN) or a Metropolitan Area Network (MAN), the connections can be wired, wireless or an hybrid of the two. Wired networks deploy the use of cables to link communicating devices. Although a good cabled network guarantees good speed, throughput, high data rate and is void of over the air interferences, structural cabling of offices and environments not originally designed to support a cabling network can itself pose a serious problem. In the alternative, is the flexible, easy to deploy, limited mobility enabled, faster implementable and affordable wireless counterpart WLAN. Wireless means of networking are the most widely deployed access network technologies in the Internet. The most popular of the wireless LANs technologies is the IEEE 802.11 wireless LAN, known also as Wi-Fi. There are several flavours of Wi-Fi LAN namely IEEE 802.11a, IEEE 802.11b, IEEE 802.11g, IEEE 802.11n, and IEEE 802.11 ac [1], [2], [3], and [4].

Several researches have been carried out to model the characteristics of WiFi signals, and as a result, specifications such as in [4], [5], and [6] have been proposed, this work aims to contribute to the development of these specifications. 


\section{RESEARCH METHODOLOGY}

The research work was carried out in Akwa Ibom State University (AKSU) Main Campus located at Ikot Akpaden, Mkpat Enin Local Government Area in Akwa Ibom State. Akwa Ibom is one of the states in South-South region of Nigeria and shares boundaries with the Atlantic Ocean, Cross River State, Abia State and Rivers State. Akwa Ibom State University (AKSU) terrain is swampy in nature and consists of several vegetation and foliage, which may cause obstructions to signal propagation. For the purpose of this work, the AKSU main campus was classified as a suburban community which consisted of students and staff, buildings, offices and lecture halls as well as sparsely located storey buildings and trees. Field measurements were carried out in the dry season within the month of January 2017.

\subsection{HARDWARE AND SofTWARE SETUP.}

To realise the objectives of the work, few devices and software were deployed. Hardware used in the experiments consisted of two laptops, spectrum analyzer, GPS, $2.4 \mathrm{GHz}$ WI-Fi radios and basic tools like measuring tape, pen and paper, for recording and measuring the areas and distances used in the propagation measurements. Table 1 states the hardware specifications deployed during the empirical measurement.

Table 1. Hardware Specifications

\begin{tabular}{clcc}
\hline S/N & Hardware Name & Brand & Model \\
\hline 1. & Laptop 1 & $\begin{array}{c}\text { Hewlett Packard } \\
\text { (HP) }\end{array}$ & HP1000 \\
2. & Laptop 2 & DELL & $\begin{array}{c}\text { Inspiron } 153000 \\
\text { Series }\end{array}$ \\
3. & Wi-Fi radio & TP-LINK & TL-WR940N \\
4. & Measuring tape & & $30 \mathrm{~m} \mathrm{TB-03}$ \\
\hline
\end{tabular}

The following software applications were also used for some specific functions such as; The InSSIDer was used to measure the signal strength and detect access points within the surroundings of laptop placement. The software identifies hardware vendor of APs, channels used, name of the network, security protocol in-use and frequency channel used by such AP. The TamoSoft Throughput Test was used for continuous sending of TCP and UDP data streams across the wireless network, it computed very important metrics such as upstream and downstream throughput values, packet loss and round-trip time, and then displays the results in both numeric and chart formats. The software supported both IPv4 and IPv6 connections and allowed network performance to be evaluated depending on the Quality of Service (QoS) settings. The Microsoft Visio was used to draw the floor plans of the buildings where indoor empirical measurements were done for the purpose of this report.

\subsection{INDOOR MEASUREMENT SiTES}

The measurements were carried out in different indoor environment including the Electrical and Electronic Engineering Lecture Halls -Hall $1 \&$ Hall 2 both on the first floor of the University Engineering Block adjacent to the ICT Building of the University and the Engineering Drawing Studio opposite the SIWES Unit of the University. The empirical measurements were first done in a wall-free scenario, where two laptops were placed in the same hall and connected to each other through TLWR940N Wireless N Router, and packets were transmitted from one laptop (server) to 
International Journal of Wireless \& Mobile Networks (IJWMN) Vol. 11, No. 2, April 2019

the other laptop(client). The floor plans of two of the buildings are shown in Figure 1. and Figure 2 . The Figures show the position of the AP during the measurement tests.

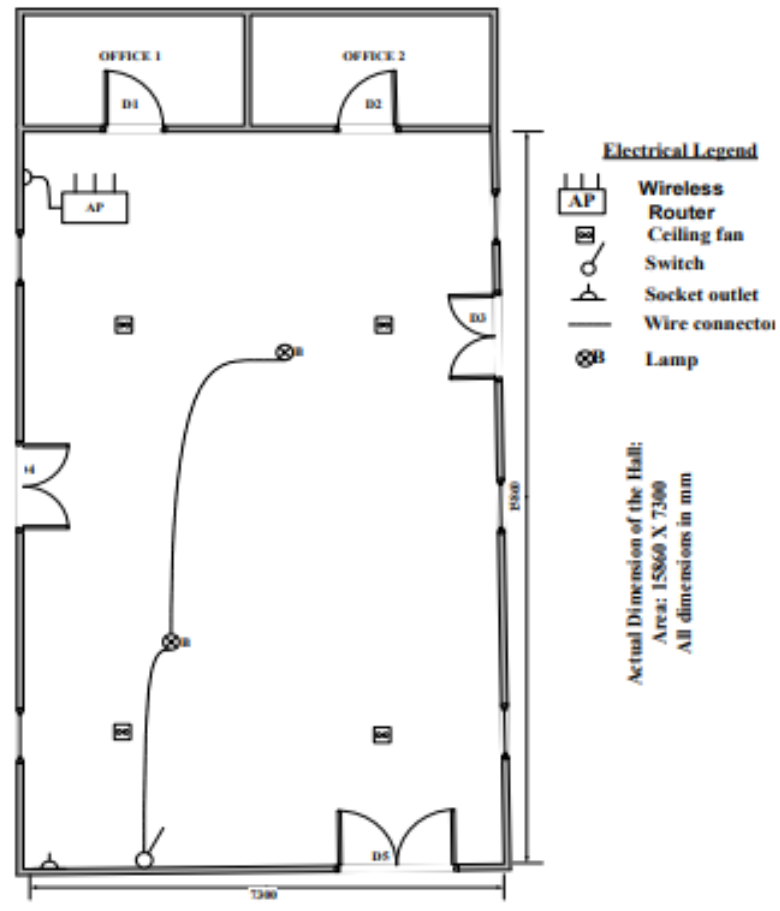

Figure 1. Floor Plan of Engineering Drawing Studio

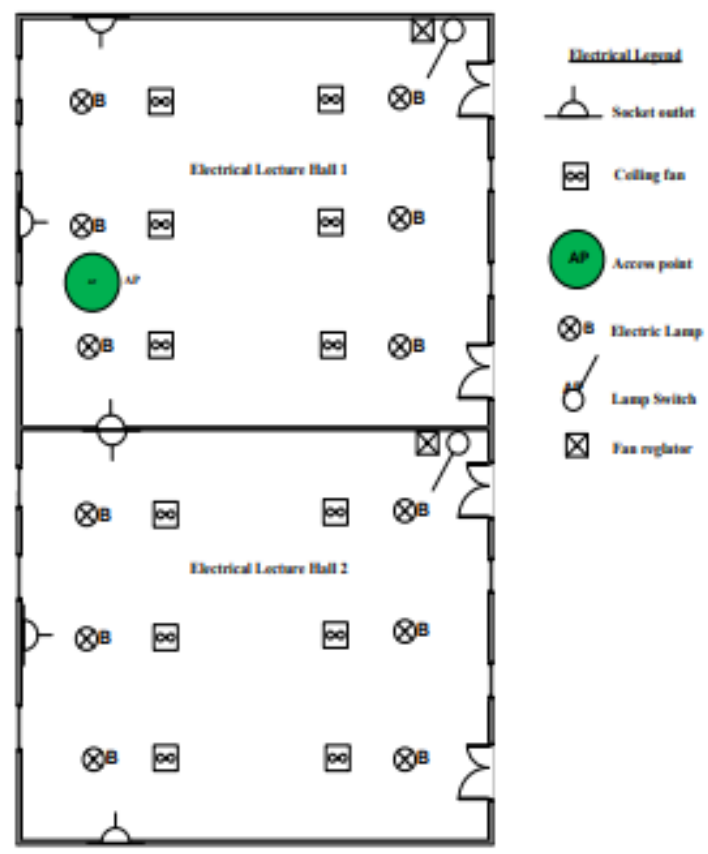

Figure 2. Floor Plan Sketch of E\&E Engineering Lecture Hall 


\subsection{Data Collection Procedure}

The hardware set-up was done in different indoor environments to accommodate for different sizes of blocks (such as wall-free scenarios, 4" blocks, 5" blocks, 6" blocks and 9" blocks). In the halls and offices, a 300Mbps Wireless-N Router (TL-WR940N TP-LINK Wi-Fi radio) was set up in one hall and two laptops connected wirelessly. TamoSoft Throughput Test software was used to measure the throughput between the laptop running as a server and the other laptop running the client application at the respective halls and offices. In the same vein, InSSIDer software was launched in the hall/office with the AP in the other hall and the received signal strength was measured accordingly. The procedures were carried out in different buildings, which are made up of different sizes of blocks. To also carry out the performance effect of Wi-Fi signal with respect to distance in the indoor scenario, the AP was set up in TETFUND Pavilion 1 and the signal strength measured as the distances were increased at the interval of $10 \mathrm{~m}$ in the hall.

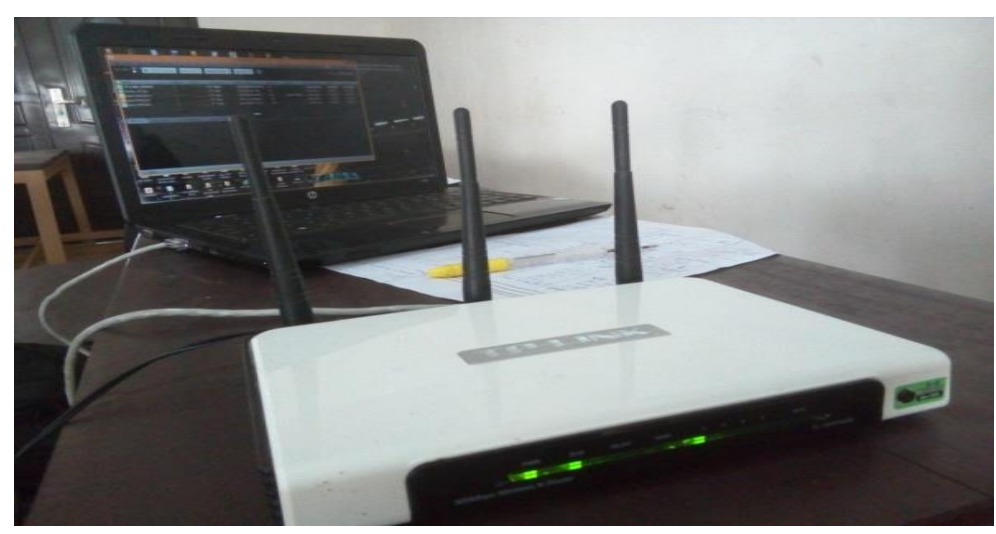

\section{Result Analysis and Presentation}

Figure 3. Indoor Transmission Experimental Set-up

In the last section, the methodology used for obtaining the data was presented. The results obtained is herein analysed and presented graphically through the application of existing mathematical models and MATLAB programs.

\subsection{Signal Strength AND ThroughPUT For VARious Sizes of Concrete Blocks}

To investigate the throughput and attenuation effect of signal with respect to different sizes of blocks, empirical measurements were carried out in offices and other buildings made of the various sizes under investigation. The average values of results obtained from multiple tests measurements is as shown below. 
International Journal of Wireless \& Mobile Networks (IJWMN) Vol. 11, No. 2, April 2019

Table 2. Throughput for different block Scenarios

\begin{tabular}{llllll}
\hline Parameters & $\begin{array}{l}\text { Wall- } \\
\text { free }\end{array}$ & $\begin{array}{l}4^{\prime \prime} \\
\text { block }\end{array}$ & $\begin{array}{l}5^{\prime \prime} \\
\text { block }\end{array}$ & $\begin{array}{l}6^{\prime \prime} \\
\text { block }\end{array}$ & $\begin{array}{l}9^{\prime \prime} \\
\text { block }\end{array}$ \\
\hline $\begin{array}{l}\text { TCP uplink } \\
\text { (Mbps) }\end{array}$ & 1.97 & 1.35 & 1.22 & 0.12 & 0.10 \\
$\begin{array}{l}\text { TCP } \\
\text { downlink }\end{array}$ & 1.97 & 1.89 & 1.88 & 0.07 & 0.03 \\
$\begin{array}{l}\text { (Mbps) } \\
\text { UDP uplink }\end{array}$ & 1.81 & 1.45 & 1.31 & 0.08 & 0.05 \\
$\begin{array}{l}\text { (Mbps) } \\
\begin{array}{l}\text { UDP } \\
\text { downlink } \\
\text { (Mbps) }\end{array}\end{array}$ & 1.68 & 1.39 & 1.01 & 0.09 & 0.02 \\
$\begin{array}{l}\text { RTT (ms) } \\
\text { RSS (dB) }\end{array}$ & 7.1 & 7.6 & 8.7 & 16.9 & 58.2 \\
\hline
\end{tabular}

From Table 2, the plots showing the changes in throughput as the size of block changes and the attenuation effect of signal with respect to the size of block is presented as shown in Figure 4 and 5 Respectively, while Figure 6 shows the round-trip time for different block sizes.

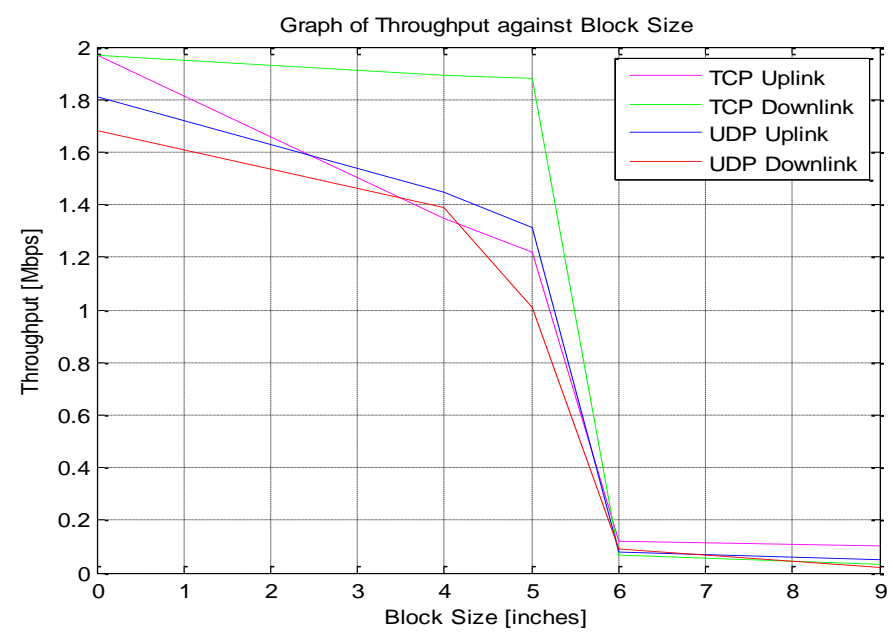

Figure 4. Changes in throughput with block sizes 
International Journal of Wireless \& Mobile Networks (IJWMN) Vol. 11, No. 2, April 2019

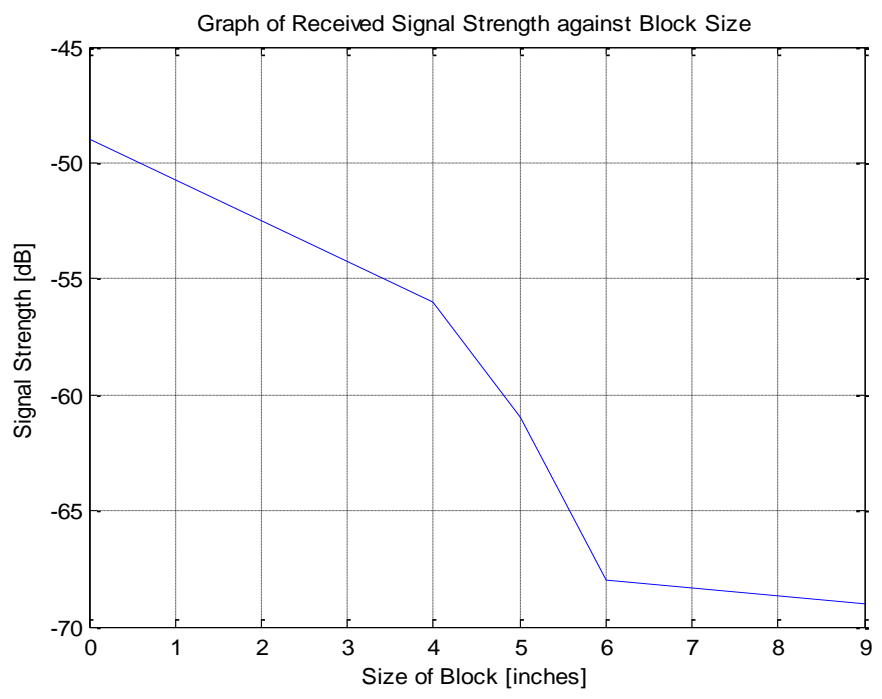

Figure 5. Graphical plot showing signal strength attenuation with block sizes

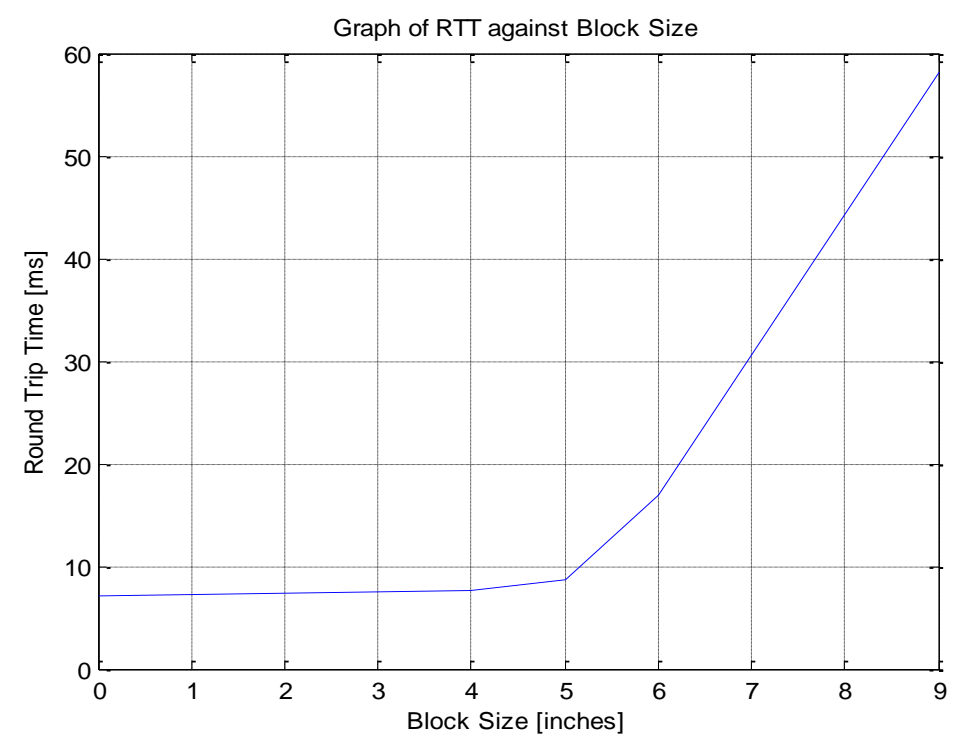

Figure 6. Graph of RTT against Block Size

\subsection{Signal Strength AND ThroughPUT MEASUREMENT FOR VARIOUS DiSTANCES IN A HALL}

Signal strength and throughput were measured with respect to distance from empirical measurements carried out in a $15.86 \mathrm{~m} \times 7.3 \mathrm{~m}$ hall, which consisted of drawing tables and other teaching facilities. The values obtained are presented in Table 3. From the values, the graphs shown in Figures 7 and 8 were plotted to investigate the performance of the system parameters within such area. 
International Journal of Wireless \& Mobile Networks (IJWMN) Vol. 11, No. 2, April 2019

Table 3. Throughput, RSS and Path Loss for varying distances

\begin{tabular}{|c|c|c|c|c|c|c|c|}
\hline \multirow[t]{2}{*}{ Distance (m) } & \multicolumn{5}{|c|}{ Throughput } & \multirow[b]{2}{*}{$\begin{array}{l}\text { RSS } \\
\text { (dB) }\end{array}$} & \multirow[b]{2}{*}{$\begin{array}{c}\text { Path Loss } \\
\text { (dB) }\end{array}$} \\
\hline & $\begin{array}{c}\text { TCP } \\
\text { Uplink } \\
\text { (Mbps) }\end{array}$ & $\begin{array}{c}\text { TCP } \\
\text { Downlink } \\
\text { (Mbps) }\end{array}$ & $\begin{array}{c}\text { UDP } \\
\text { Uplink } \\
\text { (Mbps) }\end{array}$ & $\begin{array}{c}\text { UDP } \\
\text { Downlink } \\
\text { (Mbps) }\end{array}$ & $\begin{array}{l}\text { RTT } \\
(\mathrm{ms})\end{array}$ & & \\
\hline 1 & 2.50 & 1.95 & 1.85 & 1.87 & 13.8 & -57 & 40.08 \\
\hline 2 & 2.01 & 1.94 & 1.33 & 1.52 & 17.8 & -58 & 46.10 \\
\hline 3 & 1.98 & 1.90 & 1.21 & 1.37 & 20.1 & -60 & 49.63 \\
\hline 4 & 1.72 & 1.82 & 0.91 & 1.33 & 38.6 & -61 & 52.13 \\
\hline 5 & 1.68 & 1.81 & 0.83 & 1.28 & 72.3 & -61 & 54.06 \\
\hline 6 & 1.63 & 1.75 & 0.78 & 1.11 & 108.9 & -64 & 55.65 \\
\hline 7 & 1.55 & 1.73 & 0.63 & 1.05 & 112.5 & -68 & 56.99 \\
\hline 8 & 1.48 & 1.68 & 0.59 & 0.99 & 114.7 & -70 & 58.13 \\
\hline 9 & 1.35 & 1.66 & 0.55 & 0.83 & 125.8 & -73 & 59.17 \\
\hline 10 & 1.21 & 1.63 & 0.53 & 0.79 & 130.9 & -75 & 60.08 \\
\hline 11 & 1.02 & 1.52 & 0.50 & 0.66 & 131.8 & -76 & 60.91 \\
\hline 12 & 0.99 & 1.48 & 0.48 & 0.51 & 133.1 & -77 & 61.67 \\
\hline 13 & 0.93 & 1.37 & 0.46 & 0.48 & 137.4 & -78 & 62.37 \\
\hline 14 & 0.74 & 0.99 & 0.44 & 0.46 & 139.6 & -78 & 63.01 \\
\hline
\end{tabular}

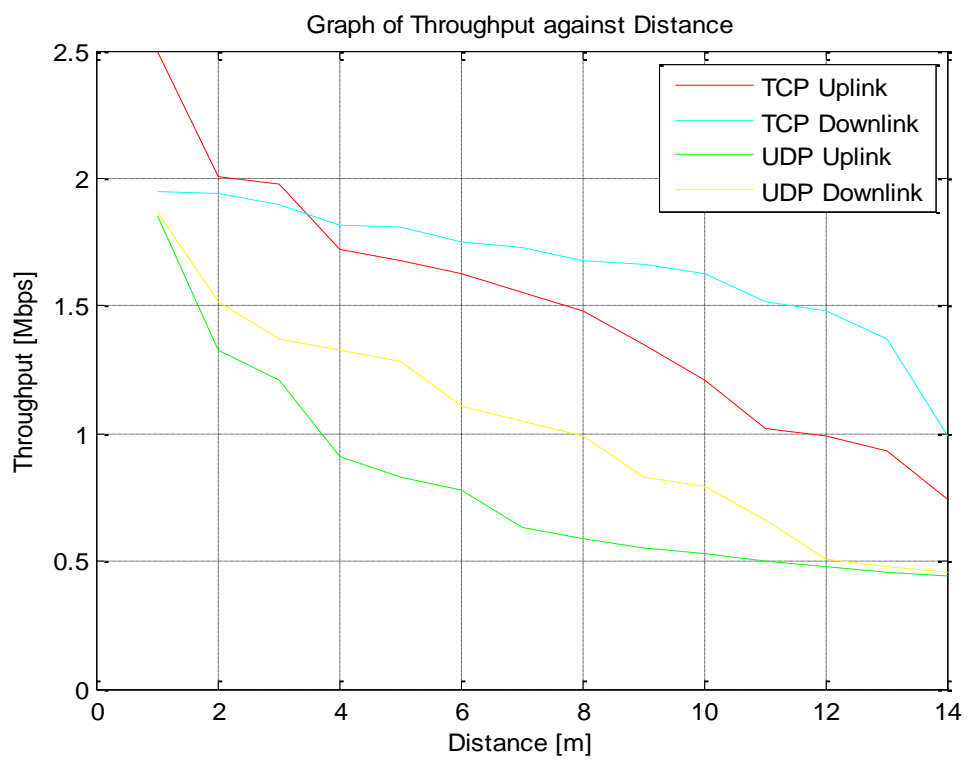

Figure 7. Graph showing changes in throughput with respect to distance 


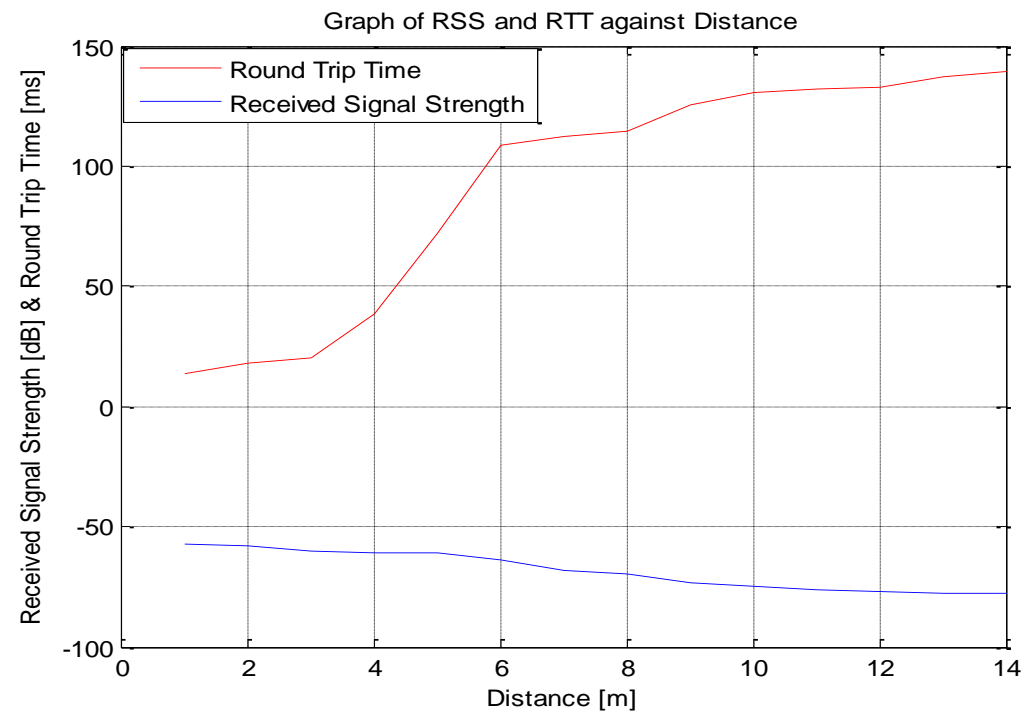

Figure 8. Graph of RSS and RTT against distance

\subsection{COMPUTATION USING LineAR REgRESSION METHOD}

Computation of the path loss exponent was done for the indoor environment using linear regression on measurements taken at the Engineering Drawing Studio of the University at the Ikot Akpaden Main Campus and applied to the values shown in Table 3.

Linear regression is given by [7]:

$$
E(\gamma)=\sum_{i=1}^{K}\left[L_{P}\left(d_{i}\right)-\widehat{L_{P}}\left(d_{i}\right)\right]^{2}
$$

Where: $L_{P}\left(d_{i}\right)$ is the measured path loss and $\widehat{L_{P}}\left(d_{i}\right)$ is the estimated path loss where

$$
P_{L}(d B)=P_{L}\left(d_{0}\right)+10 \gamma \log _{10}\left(\frac{d}{d_{0}}\right)
$$

Substituting equation 3.2 into 3.1 , we have

$$
E(\gamma)=\sum_{i=1}^{K}\left[L_{P}\left(d_{i}\right)-L_{P}\left(d_{o}\right)-10 \gamma \log _{10}\left(\frac{d_{i}}{d_{0}}\right)\right]^{2} \ldots . .3 .3
$$

The maximum value of $E(\gamma)$ would occur if $\frac{d E(\gamma)}{d \gamma}=0$, hence differentiating $E(\gamma)$ and equating the result to zero, the path loss exponent was determined as:

$$
\gamma=\frac{\sum_{i=1}^{K}\left[L_{P}\left(d_{i}\right)-L_{P}\left(d_{o}\right)\right]}{\sum_{i=1}^{K} 10 \log _{10}\left(\frac{d_{i}}{d_{0}}\right)}
$$

From Table 3.2, the path loss exponent for indoor environment within Akwa Ibom State University was calculated using equation 3.4 as 


$$
\gamma=\frac{218.86}{109.434}=1.999
$$

\subsection{DETERMINATION OF SHADOW FADING FACTOR}

As the indoor environment consisted of some smooth and rough surfaced facilities, signal propagation may be affected by some propagation mechanisms such as reflection, diffraction and scattering. To compensate for these mechanisms, shadow fading factor was calculated using standard deviation approach as follows:

From Equation 3.2 above, the large scale average path loss was predicted at a distance of $6 \mathrm{~m}$ as:

$P_{r}=P_{L}(d B)=40.08+19.99 \log _{10}\left(\frac{6}{1}\right)=55.64 d B$

Table 4. Relationship between measured and predicted path loss

\begin{tabular}{|c|c|c|c|}
\hline Distance (m) & $P_{m}(d B)$ & $\begin{array}{c}\left(P_{m}-P_{r}\right) \\
(d B)\end{array}$ & $\left(P_{m}-P_{r}\right)^{2}(d B)^{2}$ \\
\hline 1 & 40.08 & -15.56 & 242.1136 \\
\hline 2 & 46.10 & -9.54 & 91.0116 \\
\hline 3 & 49.63 & -6.01 & 36.1201 \\
\hline 4 & 52.13 & -3.51 & 12.3201 \\
\hline 5 & 54.06 & -1.58 & 2.4964 \\
\hline 6 & 55.65 & -0.01 & 0.0001 \\
\hline 7 & 56.99 & 1.35 & 1.8225 \\
\hline 8 & 58.13 & 2.49 & 6.2001 \\
\hline 9 & 59.17 & 3.53 & 12.4609 \\
\hline 10 & 60.08 & 4.44 & 19.7136 \\
\hline 11 & 60.91 & 5.27 & 27.7729 \\
\hline 12 & 61.67 & 6.03 & 36.3609 \\
\hline 13 & 62.37 & 6.73 & 45.2929 \\
\hline \multirow[t]{2}{*}{14} & 63.01 & 7.37 & 54.3169 \\
\hline & & . & $\sum\left(P_{m}-P_{r}\right)^{2} 538.0026$ \\
\hline
\end{tabular}

Standard deviation was obtained thus:

$$
\sigma=\sqrt{\frac{\sum_{k=1}^{n}\left(P_{m}-P_{r}\right)^{2}}{\mathrm{~N}}}
$$

Where $P_{m}$ is the measured path loss and $P_{r}$ the predicted path loss, while $\mathrm{N}$ is the number of data points measured.

$$
\sigma=\sqrt{\frac{538.0026}{14}}=6.20 \mathrm{~dB}
$$

The shadow fading factor as a Gaussian distribution was determined by using standard normal curve. From the curve, it was observed that the shadow factor must be less than or equal to $12.40 \mathrm{~dB}$ since the probability of $95 \%$ is acceptable in practical scenario. Hence, the random normal variable $X_{\sigma}$ was determined using cumulative density function given as: 


$$
\phi\left(\frac{X_{\sigma}-\mu}{\sigma}\right)=0.95
$$

The mean value $(\boldsymbol{\mu})$ of $0 \mathrm{~dB}$ was used, from the normal distribution table the value of $\mathrm{z}$ that corresponds to $\phi(\mathrm{z})=0.95$ is given as 1.65 . Therefore,

$$
\frac{\mathrm{X}_{\sigma}-0}{6.20}=1.65 ; \quad X_{\sigma}=10.23 \mathrm{~dB}
$$

With this value, the path loss beyond reference distance is given by,

$$
P_{L}(d B)=40.08+19.99 \log _{10}\left(\frac{d}{d_{0}}\right)+10.23
$$

\subsection{COMPARISON WITH EXISTING MODELS}

Since IEEE802.11b standard and channel 1 was used, then the corresponding centre frequency of $2412 \mathrm{MHz}$ was used in the path loss analysis. Using the indoor path loss model such as Wall and floor factor, ITU and Free space models, and substituting the heights $h_{b}=5 m, h_{m}=1.5 m$ the analysis shown below was carried out.

Wall and Floor path loss model is:

$$
L_{d B}=P_{L}\left(d_{0}\right)+20 \log _{10}(d)+n_{f} a_{f}+n_{w} a_{w}
$$

Where: $n_{f}$ and $n_{w}$ are the number of floors and walls, $a_{f}$ and $a_{w}$ are the attenuation factor per floor and wall. In the experiment there was no wall and floor separating the access point and the mobile device, therefore equation (3.8) reduces to:

$$
L_{d B}=40.08+20 \log _{10}(d)
$$

ITU model equation is:

$$
L_{d B}=20 \log _{10}\left(f_{c}[M H z]\right)+10 n \log _{10}(d[m])+L_{f}\left(n_{f}\right)-28
$$

Where: $L_{f}\left(n_{f}\right)$ is floor penetration factor.

Since the AP and the mobile device were on the same floor, then $L_{f}\left(n_{f}\right)=0$

$$
\begin{gathered}
L_{d B}=20 \log _{10}(2412)+10 n \log _{10}(d[m])-28 \\
L_{d B}=39.65+19.99 \log _{10}(d[m]) \ldots \ldots \ldots \ldots \ldots \ldots \ldots \ldots \ldots \ldots \ldots \ldots \ldots \ldots \ldots \ldots \ldots \ldots
\end{gathered}
$$

Free space model is:

$$
\begin{array}{r}
L_{d B}=20 \log _{10}\left(f_{c}[\mathrm{MHz}]\right)+20 \log _{10}(d[\mathrm{~m}])+32.44 \\
L_{d B}=100.04+20 \log _{10}(d[\mathrm{~m}]) \ldots \ldots \ldots \ldots \ldots \ldots \ldots \ldots \ldots \ldots \ldots \ldots \ldots \ldots \ldots \ldots \ldots \ldots \ldots \ldots \ldots \ldots
\end{array}
$$

Using the values of the measured distance and the equations 3.8, 3.9, 3.10 and 3.11, the graph shown in Figure 9 was plotted with the help of MATLAB program. 


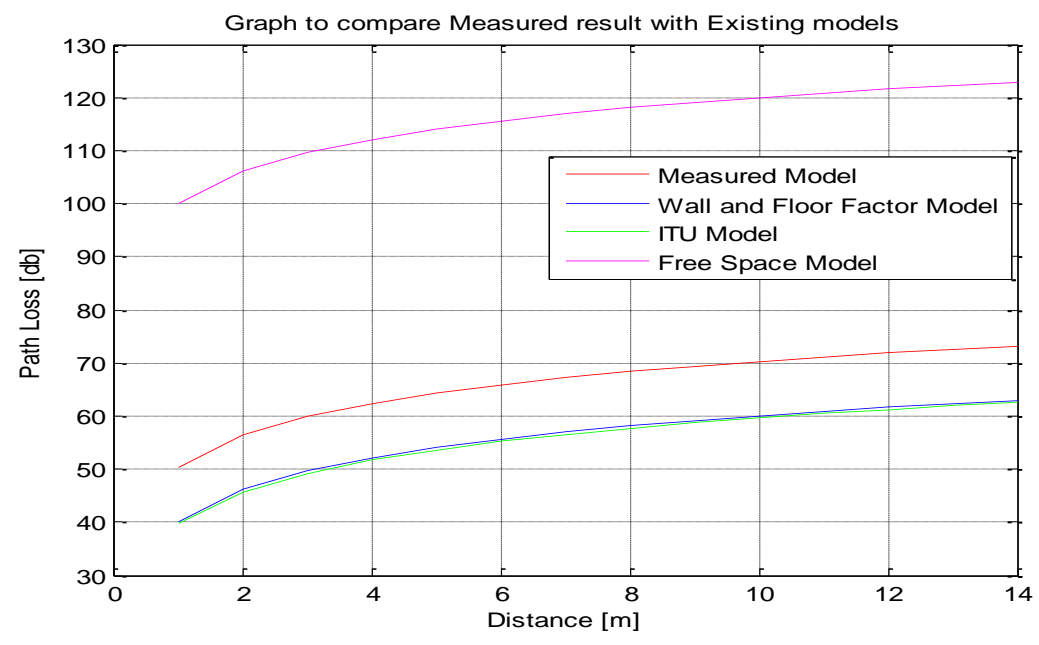

Figure 9. Graph to compare the measured result with existing models

\section{Conclusions}

From Table 2 and Figures 4, 5 and 6, it is evident that WiFi signal attenuation increases with increase in block size as seen with the increase in the round trip time as well as the reductions in the received Signal strengths and TCP and UDP throughputs. The measurements did not include full concretized wall as there was none as at the time of this measurements. It is therefore pertinent to consider the sizes of block walls in the design of multi-rooms indoors applications. Table 3 and Figures 7 and 8 confirm a well-established relationship between the Path-loss and distance. The targeted QoS should therefore inform the acceptable coverage distance within halls in the University campus. The indoor Path-loss was characterized to $P_{L}(d B)=40.08+$ $19.99 \log _{10}\left(\frac{d}{d_{0}}\right)+10.23$ with an exponent of 1.999. Comparing the measured path loss with Free Space, Wall and Floor Factor and ITU models shows clear disparity as the Wall and Floor Factor and ITU models are lower than the measured model while the Free Space model is very much higher than the measured model. The errors between the free space model, Wall and Floor Factor model and ITU model are $53.54 \mathrm{~dB}, 6.42 \mathrm{~dB}$ and $6.85 \mathrm{~dB}$ respectively. It is therefore more accurate to stick to the measured model for proper indoor network planning within the terrain.

\section{REFERENCES:}

[1] T.S. Rappaport, (1996) Wireless Communications Principles and Practice. Prentice Hall.

[2] William Stallings, (2002) Wireless Communications and Networks. Prentice Hall.

[3] IEEE. (1997) Wireless LAN medium access control (MAC) and physical layer (PHY) specifications. IEEE Standard 802.11.

[4] G.A. Halls, (1994) HIPERLAN: the high performance radio local area network standard. Electronics and Communication Engineering Journal, 6:289-296.

[5] IEEE, (2003) Wireless LAN medium access control (MAC) and physical layer (PHY) specifications Amendment 4: Further higher-speed physical layer extension in the $2.4 \mathrm{GHz}$ band. IEEE Standard 802.11g. 
[6] IEEE, Wireless LAN medium access control (MAC) and physical layer (PHY) specifications Amendment 2: Higher speed physical layer (PHY) extension in the $2.4 \mathrm{GHz}$ band. IEEE Standard 802.11b.

[7] Ubom, E.A., Idigo, V. E., Azubogu, A.C.O., Ohaneme, C.O., and Alumona, T. L. (2011) "Path loss Characterization of Wireless Propagation for South - South Region of Nigeria". International Journal of Computer Theory and Engineering, Vol. 3, No. 3.pp

[8] Jin-Shyan Lee and Yuan-Ming Wang (2013) Experimental Evaluation of ZigBee-Based Wireless Networks in Indoor Environments, Hindawi Publishing Corporation, Journal of Engineering, http://dx.doi.org/10.1155/2013/286367. 